\title{
A computational pipeline for diagnostic biomarker discovery in the human pathogen Trypanosoma cruzi
}

\author{
Santiago J Carmona ${ }^{1 *}$, Paula Sartor², Maria Susana Leguizamón², Oscar Campetella ${ }^{1}$, Fernán Agüero' \\ From Sixth International Society for Computational Biology (ISCB) Student Council Symposium \\ Boston, MA, USA. 9 July 2010
}

\section{Background}

The protozoan parasite Trypanosoma cruzi is the causative agent of Chagas' disease, endemic in 18 countries in Central and South America. Transmission also occurs in non-endemic countries by way of blood transfusion and organ transplantation. Diagnosis of American trypanosomiasis is based on the detection of antibodies directed against $T$. cruzi antigens. In this work we mined the
T. cruzi genome sequence to identify new peptidic diagnostic biomarkers.

\section{Methods}

An integrative bioinformatic strategy was adopted to prioritize peptidic antigens with low cross-reactivity in the genome of T. cruzi. A computational pipeline was developed to assess a set of molecular properties on

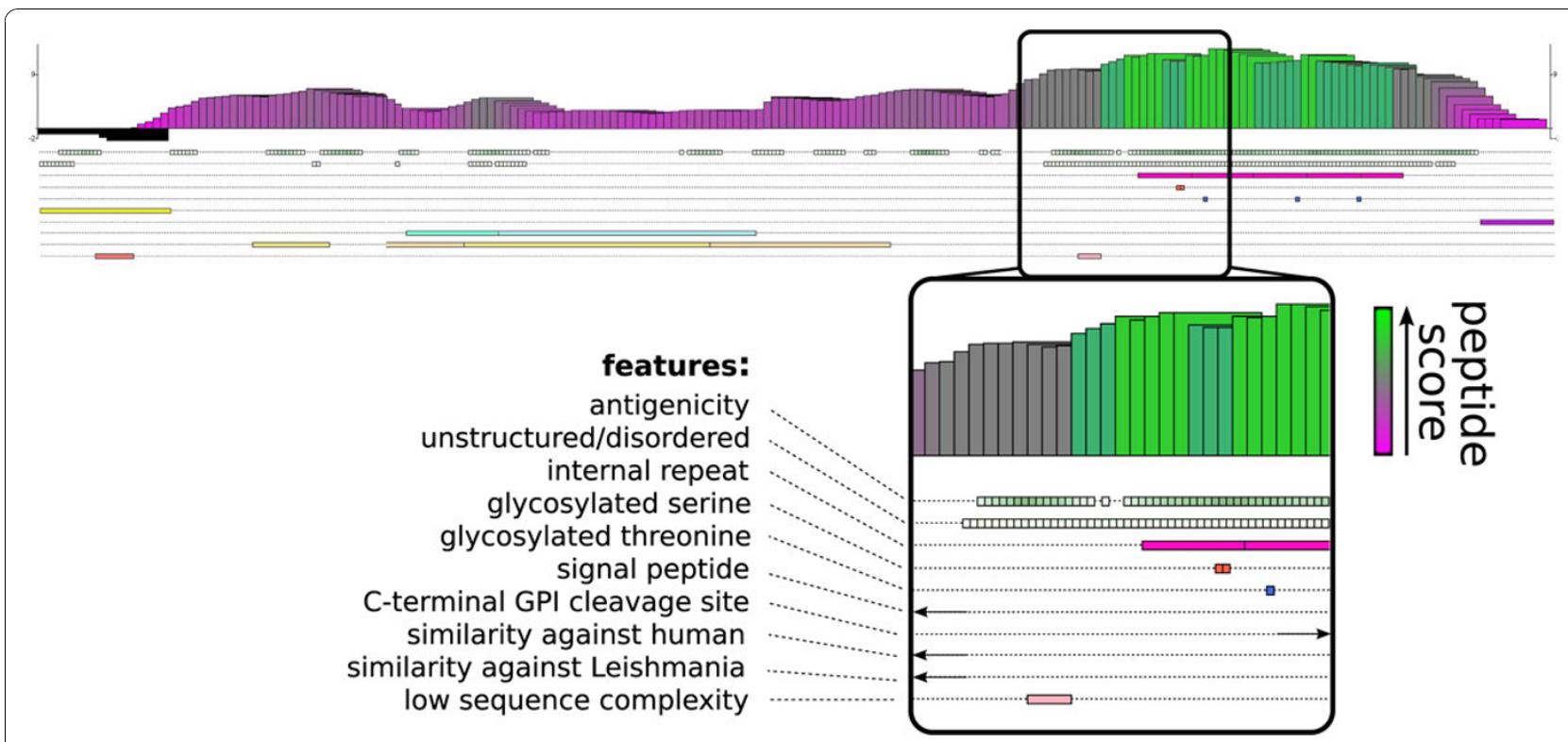

Figure 1 Example sequence profile generated by the pipeline using BioPerl. Vertical boxes in the plot represent overlapping 12-residue peptides, and its height and colour, the resulting score based on the mapped features shown below.

* Correspondence: sjcarmona@gmail.com

Full list of author information is available at the end of the article 
each protein from the reference $T$. cruzi genome, such as subcellular localization or expression level (by mass spec. evidence, number of gene copies and synonymous codon usage bias). At a higher resolution, a set of local properties were evaluated, such as repetitive motifs, disorder (structured vs natively unstructured regions), trans-membrane spans, glycosylation sites, polymorphisms (conserved vs. divergent regions), predicted B-cell epitopes, sequence similarity against human proteins and Leishmania (potential cross-reacting species) (Figure 1). A scoring function based on these properties was used to rank each of the $\sim 10$ million 12-residue overlapping peptides in which the $\sim 22,000 \mathrm{~T}$. cruzi proteins can be virtually fragmented. Experimental validation of predicted epitopes was performed with peptide microarrays, screened using pooled sera from human chagasic patients and controls.

\section{Results}

We show that our integrative method outperforms alternative antigen prioritizations based on individual properties (such as B-cell epitope predictors alone). Our genome-wide prioritization uncovered more than 300 promising biomarker candidates. 200 high-scoring peptides corresponding mostly to hypothetical proteins were selected for immunological validation, along with 40 peptides derived from previously validated B-cell epitopes and an additional set of 40 low-scoring peptides as controls. Preliminary results based on microarray images revealed that $\sim 25 \%(49 / 200)$ of the candidate peptides reacted specifically against the positive sera pools assayed.

\section{Conclusion}

The developed bioinformatic approach proved to be successful, leading from a genome-wide prioritization to the identification of novel peptidic antigens with diagnostic potential. Moreover, the algorithm may be used to prioritize biomarkers in other pathogen species.

\section{Acknowledgements}

This work was funded by Universidad de San Martín (grant PROG07F/1) and the "Special Programme for Research and Training in Tropical Diseases (UNICEF/UNDP/World Bank/WHO)".

\section{Author details}

${ }^{1}$ Instituto de Investigaciones Biotecnológicas, Universidad de San Martín, San Martín, Argentina. ${ }^{2}$ Departamento de Microbiología, Facultad de Medicina, Universidad de Buenos Aires, Buenos Aires, Argentina.

Published: 7 December 2010

doi:10.1186/1471-2105-11-S10-011

Cite this article as: Carmona et al:: A computational pipeline for diagnostic biomarker discovery in the human pathogen Trypanosoma cruzi. BMC Bioinformatics 2010 11(Suppl 10):011.

\section{Submit your next manuscript to BioMed Central and take full advantage of:}

- Convenient online submission

- Thorough peer review

- No space constraints or color figure charges

- Immediate publication on acceptance

- Inclusion in PubMed, CAS, Scopus and Google Scholar

- Research which is freely available for redistribution 